\title{
Making every baby count: Reflection on the Helping Babies Breathe Program to reduce birth asphyxia in sub-Saharan Africa
}

For decades, the world has seen an overwhelming number of neonatal deaths. In 2015 alone, the UN inter-agency estimation group estimated 19.2 deaths per every 1000 births ${ }^{[1]}$ the majority of which come from low- and middle-income countries (LMIC) in South East Asia and sub-Saharan Africa. ${ }^{[2]}$ Birth asphyxia, a condition traditionally referred to as the inability of a full-term baby to adequately establish breathing at birth, interrelated with other acute intrapartum events, ${ }^{[3]}$ accounts for 717000 deaths each year and is the second leading cause of neonatal deaths, ${ }^{[4]}$ of which $85 \%$ are experienced in LMIC. ${ }^{[4]}$ The Helping Babies Breathe Program (HBBP) is a global response to asphyxia that was endorsed by the World Health Organization (WHO). It was first introduced by the American Academy of Pediatricians (AAP) in partnership with USAID and Save the Children. ${ }^{[5]}$ After nearly 6 years of implementation, this paper takes a critical look at this programme in sub-Saharan Africa.

\section{Global response to asphyxia through the HBBP}

In response to the global increase in neonatal mortality, ${ }^{[6]}$ the WHO and the AAP launched the HBBP in $2010 .{ }^{[5]}$ Key to this intervention was capacity building of skilled birth attendants using simulation-based methods. ${ }^{[5]}$ By the end of 2015, 42 countries in subSaharan Africa had scaled up the HBBP nationally. ${ }^{[2]}$

However, to date, complementary government strategies to support basic newborn care have not been implemented effectively and therefore many targets have not been reached in most African countries. ${ }^{[7]}$ Dickson et al. ${ }^{[7]}$ observed that investments towards establishing robust health information systems to capture the magnitude of birth asphyxia in most African countries had lagged. This undoubtedly has had policy implications as only $47 \%$ of African countries had prioritised birth asphyxia in the respective national maternal, neonatal and child health policies. ${ }^{[8]}$

\section{Health systems - can the centre hold with just the HBBP?}

One critical factor to improve on is a strengthened healthcare system that delivers safe and quality service intra- and postpartum. ${ }^{[9]}$ Lawn et al. ${ }^{[8]}$ in a study of 32 countries, observed that only $10 \%$ of national health programmes adequately incorporated components of Comprehensive Emergency Obstetric and Newborn Care (CEmONC) into routine maternal healthcare. Similarly, a study conducted in Tanzania identified overpopulation of babies in a maternity ward, understaffing, and the absence of essential equipment, as the leading causes of 40 asphyxia-induced deaths. ${ }^{[10]}$ Penwell ${ }^{[11]}$ classified these factors as a violation of fundamental human rights to life.

To achieve the golden minute, ${ }^{[1]}$ the AAP recommends that health centres and hospitals have basic resuscitative equipment at every level of care. ${ }^{[5]}$ Sadly, progress in this regard has fallen below expectation in many countries. In Malawi for instance, 6 years after scaling up the HBBP nationally, ${ }^{[12]}$ data from the service provision assessment showed that the basic equipment to support sustainability of the programme was inadequate at almost every level of care (Table 1). ${ }^{[13]}$ Table 1 gives a further insight on the state of affairs.

The resounding question that emanates from Table 1 is how can the fight against asphyxia be won when basic equipment such as single suction apparatus is lacking in clinics? How can HBB training make an

indelible impact when a manual vacuum extractor is absent in a health facility?

Another crucial area in the fight against asphyxia is an effective referral system that responds to emergencies in a timely fashion. ${ }^{[7]}$ According to Hussein et al., ${ }^{14]}$ there is a significant negative correlation between effective referral system and neonatal deaths (odds ratio (OR) 0.56; 95\% confidence interval (CI) 0.32 - 0.96). Similarly, Pembe et al. ${ }^{[15]}$ posit that implementing an effective referral mechanism has almost twice the potential of reducing risk factors of severe neonatal complications (OR 1.6; 95\% CI 0.34 - 7.8). Nevertheless, ineffective referral systems continue to hamper neonatal health especially in rural facilities. For instance, a study in rural facilities found that $62.5 \%$ with neonatal deaths were directly associated to late referrals due to transportation bottlenecks. ${ }^{[10]}$

Community surveillance has been identified by Kilonzo et al. ${ }^{[16]}$ as a prime factor necessary for well-coordinated and effective public health planning. Yet, fragmented community surveillance in most African countries has created an overwhelming deficit in planning for overall neonatal and maternal public health. ${ }^{[17]}$ For

Table 1. Availability of basic resuscitation equipment and essential medicine in Malawi ${ }^{114}$

\begin{tabular}{llll}
\hline & \multicolumn{3}{c}{ Availability, $\boldsymbol{n}(\%)$} \\
\cline { 2 - 4 } Item & $\begin{array}{l}\text { District } \\
\text { and Central } \\
\text { Hospitals }\end{array}$ & Health Centre & Clinic \\
\hline Availability of IMPAC guidelines & $17(56.7)$ & $182(43.3)$ & $8(44.4)$ \\
Emergency transport & $6(14.4)$ & $141(9.8)$ & $10(20.4)$ \\
Suction apparatus (mucus extractor) & $18(60.0)$ & $308(73.3)$ & $13(72.2)$ \\
Manual vacuum extractor & $19(67.9)$ & $136(32.4)$ & $4(22.2)$ \\
Vacuum aspirator or D\&C kit & $14(58.3)$ & $74(17.6)$ & $3(16.7)$ \\
Availability of essential medicines for & & & $17(94.4)$ \\
delivery & & $400(95.2)$ & $10(55.6)$ \\
Injectable uterotonic (oxytocin) & $27(96.4)$ & $211(50.2)$ & $5(27.8)$ \\
Injectable antibiotic & $23(82.1)$ & $362(86.2)$ & $11(61.1)$ \\
Injectable magnesium sulphate & $28(100)$ & $334(79.5)$ & $9(50.0)$ \\
Injectable diazepam & $25(89.3)$ & $216(51.40)$ & $14(77.8)$ \\
Skin disinfectant & $21(75.0)$ & $281(66.9)$ & \\
Intravenous fluids with infusion set & $20(71.4)$ & &
\end{tabular}


instance, a study in Tanzania found that the fragmented nature of documenting neonatal outcomes at birth had resulted in high rates of uncompleted perinatal registers. ${ }^{[10]}$ Integration of $\mathrm{MNCH}$ data is the first step towards ensuring a community surveillance strengthening backed with strong data management teams at every level of care. In this instance, Ghana's approach to community and district surveillance is worth emulating. ${ }^{[18]}$

\section{Technical challenges of the HBBP - translation into clinical practice and sustainability}

Using Kirkpatrick's model of evaluation, Ersdal et al. ${ }^{[19]}$ found that 39 skilled birth attendants trained in the implementation of the HBBP failed to translate it to clinical practice 7 months after initial training. Surprisingly, the authors further observed that the birth attendants' ability to conduct face mask ventilation (FMV) in delivery rooms had reduced from $8.4 \%$ to $7.5 \%$ after their training. Similar to this finding, an evaluation of the HBBP in Malawi found that only $57.1 \%$ of healthcare workers could attain the golden minute 1 year after training. ${ }^{[12]}$

High rates of attrition among healthcare workers ${ }^{[12]}$ and inadequate local funding streams ${ }^{[20]}$ have been identified as the prevailing threats to sustaining the HBBP. Until 2015, donors had been the main funders of the HBBP, with $>80 \%$ of funding for the programme coming from a consortium of private and international donor organisations. ${ }^{[5]}$ Almost 17 years after the Abuja declaration, only Rwanda has committed a minimum $15 \%$ of its total budget to healthcare provision. ${ }^{[21]}$ Lessons from other developing countries after the post Global Fund to fight AIDS, Tuberculosis and Malaria funding has taught us the ramifications of having donor-dominated health programmes. Staff attrition continues to threaten the sustainability of the HBBP. In Tanzania, Sepeku and Kohi ${ }^{[10]}$ found that 1 year after implementation of the HBBP, staff turnover had almost doubled. Likewise, in Kenya, a study found that knowledge on asphyxia management in primary healthcare facilities had dissipated, largely due to high attrition rates among healthcare workers. ${ }^{[22]}$

\section{Conclusion}

While a 1-day HBB training programme may result in skills enhancement of birth attendants, its translation into clinical practice is unassured. For this reason, a comprehensive health system-strengthening strategy will be necessary to avoid preventable neonatal deaths. It is worth acknowledging that birth asphyxia is currently the second leading cause of neonatal death, after low birth weight, ${ }^{[4]}$ and now exceeds pneumonia, making it the second leading cause of under-5 mortality as well. ${ }^{[4]}$ This implies that a comprehensive and integrated strategy for asphyxia management along with other perinatal complications will be a giant step towards the achievement of the United Nations' Sustainable Development Goal number 3 in sub-Saharan Africa.

Until sub-Saharan countries strengthen health systems and prioritise perinatal health, the expected progress of reducing under-5 mortality, while increasing life expectancy and the human development index, will remain below target. Governments must fulfil the Abuja declaration and increase health budgetary allocations to $15 \%$, alongside a minimum healthcare spending of $5 \%$. The training of perinatal specialists should be prioritised to improve the conditions of service for birth attendants in remote settings and to remove geophysical barriers to services.

Interventions at the household and community levels are crucial in reducing the possible risk factors that could affect the health of babies. For this reason, public healthcare planners should lead national efforts in educating pregnant women, especially those who are least educated. The implementation of community health workers (CHW) will be critical in achieving this objective and it would be worthwhile for other sub-Saharan countries to invest in CHW programmes, such as those in Rwanda and Nigeria. ${ }^{[23]}$
At the management level, governments should invest in efforts to provide clear-cut policies that allow training institutions to incorporate the HBBP into teaching curricula. Health authorities should prioritise quality improvement and routine in-service training as a complement to the HBBP, and focus on other perinatal capacity building programmes, such as Essential Care for Every Baby (ECEB).

It is apparent that the world's singular targeted response to asphyxia, the HBBP, is inadequate. I therefore join other colleagues to call for global action towards establishing a more integrated, comprehensive, and responsive approach to perinatal health.

\section{Emmanuel Nene Odjidja}

$M S c$

Institute for Global Health and Development, Queen Margaret University, Scotland, UK

emmaodjidja@gmail.com

S Afr J Child Health 2017;11(2):61-63. DOI:10.7196/SAJCH.2017.v11i2.1324

1. You D, Hug L, Ejdemyr S, et al. Global, regional, and national levels and trends in under-5 mortality between 1990 and 2015, with scenario-based projections to 2030: A systematic analysis by the UN Inter-agency Group for Child Mortality Estimation. 2017. https://doi.org/10.1016/S0140-6736(15)00120-8

2. Berkelhamer SK, Kamath-Rayne BD, Niermeyer S. Neonatal resuscitation in low-resource settings. Clinics Perinatol 2016;43(3):573-591. https://doi. org/10.1016/j.clp.2016.04.013

3. Lawn JE, Manandhar A, Haws RA, Darmstadt GL. Reducing one million child deaths from birth asphyxia - a survey of health systems gaps and priorities. Health Res Policy Syst 2007;5(1):4. https://doi.org/10.1186/1478-4505-5-4

4. Liu L, Johnson HL, Cousens S, et al. Global, regional, and national causes of child mortality: An updated systematic analysis for 2010 with time trends since 2000 Lancet 2012;379(9832):2151-2161. https://doi.org/10.1016/s0140-6736(12)60560-1

5. American Academy of Pediatrics (AAP). Helping Babies Survive Washington: AAP, 2010. http://www.helpingbabiesbreathe.org/ (accessed 30 September 2016).

6. Oza S, Lawn JE, Hogan DR, Mathers C, Cousens N. Neonatal cause-of-death estimates for the early and late neonatal periods for 194 countries: 2000 - 2013. Bull World Health Organ 2015,93:19-28. http://dx.doi.org/10.2471/BLT.14.139790

7. Dickson KE, Simen-Kapeu A, Kinney MV, et al. Every newborn: Healthsystems bottlenecks and strategies to accelerate scale-up in countries. Lancet 2014;384(9941):438-454. https://doi.org/10.1016/s0140-6736(14)60582-1

8. Lawn JE, Kinney M, Lee AC, et al. Reducing intrapartum-related deaths and disability: Can the health system deliver? Int J Gynecol Obstet 2009;107:S123-S142. https://doi.org/10.1016/j.ijgo.2009.07.021

9. Spector JM, Daga S. Preventing those so-called stillbirths. Bull World Health Organ 2008;86(4):315-316. https://doi.org/10.2471/BLT.07.049924

10. Sepeku A, Kohi TW. Treatment outcomes of neonatal asphyxia at a national hospital in Dar es Salaam, Tanzania. Afr J Nurs Midwifery 2011;13(2):43-56.

11. Penwell V. A hidden tragedy: Birth as a human rights issue in developing countries. Eugene: Midwifery Today, Inc., 2010. https://www.midwiferytoday. com/articles/hiddentragedy.asp (accessed 30 September 2016).

12. Gupta S, Kazembe A, Mupfudze T, et al. Evaluation of the Helping Babies Breathe (HBB) Initiative Scale-Up in Malawi. Lilongwe: Maternal and Child Survival Program 2014

13. Ministry of Health $(\mathrm{MoH})$ Malawi, ICF International. Malawi Service Provision Assessment 2013 - 14. Lilongwe, Malawi, and Rockville, Maryland, USA: $\mathrm{MoH}$ and ICF International, 2014.

14. Hussein J, Kanguru L, Astin M, Munjanja S. The effectiveness of emergency obstetric referral interventions in developing country settings: A systematic review. PLoS Med 2012;9(7):e1001264. https://doi.org/10.1371/journal. pmed.1001264

15. Pembe AB, Carlstedt A, Urassa DP, Lindmark G, Nyström L, Darj E Effectiveness of maternal referral system in a rural setting: A case study from Rufiji district, Tanzania. BMC Health Services Res 2010;10(1):326. https://doi. org/10.1186/1472-6963-10-326

16. Kilonzo A, Kouletio M, Whitehead SJ, Curtis KM, McCarthy BJ. Improving surveillance for maternal and perinatal health in 2 districts of rural Tanzania. Am J Pub Health 2001;91(10):1636-1640. https://doi.org/10.2105/ ajph.91.10.1636

17. Calain P. From the field side of the binoculars: A different view on global public health surveillance. Health Policy Plann 2006;22(1):13-20. https://doi. org/10.1093/heapol/czl035 
18. Amoakoh-Coleman M, Kayode GA, Brown-Davies C, et al. Completeness and accuracy of data transfer of routine maternal health services data in the greater Accra region. BMC Res Notes 2015;8(1). https://doi.org/10.1186/s13104-015-1058-3 19. Ersdal HL, Vossius C, Bayo E, et al. A one-day 'Helping Babies Breathe' course improves simulated performance but not clinical management of neonates. Resuscitation 2013;84(10):1422-1427. https://doi.org/10.1016/j. resuscitation.2013.04.005

20. Vossius C, Lotto E, Lyanga S, et al. Cost-effectiveness of the 'Helping Babies Breathe' program in a missionary hospital in rural Tanzania. PLoS ONE 2014;9(7):e102080. https://doi.org/10.1371/journal.pone.0102080
21. Jowett M, Brunal MP, Flores G, Cylus J. Spending targets for health: No magic number. Health financing working paper No. 1. Geneva: WHO, 2016. http://apps.who.int/iris/bitstream/10665/250048/1/WHO-HIS-HGFHFWorkingPaper-16.1-eng.pdf (accessed 29 September 2016).

22. Bang A, Patel A, Bellad R, et al. Helping Babies Breathe (HBB) training: What happens to knowledge and skills over time? BMC Pregnancy Childbirth 2016;16(1):364. https://doi.org/10.1186/1471-2393-14-116

23. Singh P, Sachs JD. 1 million community health workers in sub-Saharan Africa by 2015. Lancet 2013; 382(9889):363-365. https://doi.org/10.1016/s01406736(12)62002-9 